\title{
Jeux de maux
}

La vocation du médecin est de guérir, c'est une évidence.

Pour le médecin du sport, une évidanse.

Pour le psychiatre, une évidense.

Danse des maux.

Et alors, quand la maladie est plus rapide, plus forte, plus sournoise, nous sommes évidés.

Plus tard, il faut affronter la dépendance. A deux. Mais là, en vérité, non, le malade est tout seul ... sauf si? ...

Et tout en laissant à celui qui dépend des autres la fierté, la pudeur, il faut l'aider à marcher avec nous, à marcher droit, à ramper droit au but, à vaincre les obstacles, à aller de l'avant.

Oui, mais vers quoi? Donner l'espoir oui, mais pas celui de vivre comme avant, non, celui de continuer, ne serait-ce qu'une petite et fragile minute, celui d'être digne.

C'est le moment d'entamer, de poursuivre le terrible pas de deux engagé avec le Couché, l'Amputé, le Paralysé, le Défiguré, le Déséquilibré.

Nous ne guérissons plus, la nouvelle vocation du médecin est alors d'accompagner.

On peut être dépendant de substances, et aussi dépendant d'autres Etres Humains. Nul n'est jamais préparé à endurer cette souffrance-là.

Quand la douleur tord les traits, tenter de la dominer pour donner une chance au sourire de revenir. Un moyen d'y parvenir est de donner notre sourire. C'est difficile? Pas tant que ça ... ce qui est malaisé, c'est de le donner en toute sincérité.

Danse des morts. Ce n'est pas toujours un échec.

Dr Julia Vecsey

Rue Maunoir 6

CH-1207 Genève 